\title{
La autodefensa de masas y las Milicias Rodriguistas: aprendizajes, experiencias y consolidación del trabajo militar de masas del Partido Comunista de Chile, 1982-1987
}

\author{
Self-defense of the masses and the 'Rodriguista' Militias: lessons, experiences \\ and the consolidation of the military work of masses of the Communist Party \\ of Chile, 1982-1987
}

Jaime Reyes Soriano*

\begin{abstract}
Resumen: El artículo reconstruye el trabajo militar de masas que consolidó el Partido Comunista de Chile en los años ochenta para enfrentar a la dictadura de Augusto Pinochet, la que se plasmó en la autodefensa de masas y las Milicias Rodriguistas. Accediendo a publicaciones partidarias y algunos testimonios, buscamos interpretar que por medio de las tareas paramilitares logró materializarse la Política de Rebelión Popular de Masas, puesto que a través de la experiencia miliciana se ejerció, por una parte, actividad partidaria y, por otra, que las masas desarrollaban formas de lucha más audaces.
\end{abstract}

Palabras clave: Partido Comunista de Chile, Autodefensa de masas, Milicias Rodriguistas, Dictadura Militar

\begin{abstract}
The article reconstructs the multitudinal military work that the Communist Party of Chile consolidated in the eighties to confront the dictatorship of Augusto Pinochet, which was reflected through the development of a strategy of self-defense of the masses and the 'Rodriguista' Militias. Through access to party publications and a number of testimonies, this article seeks to interpret the paramilitary tasks, through which they were able to achieve the Politics of Popular Rebellion of the Masses, due to the fact that through the militia experience they were able to excercice party activities, as well as develop bolder forms of struggle on a mass scale.
\end{abstract}

Key words: Communist Party of Chile, Self-defense of the masses, 'Rodriguista' Militias, military dictatorship

\section{Introducción}

Durante los años ochenta el país se vio convulsionado por la crisis económica que azotó al modelo neoliberal y por las jornadas de protestas entre 1983 y 1987 . El desplome

\footnotetext{
* Chileno, Licenciado en Historia Universidad Alberto Hurtado. Este artículo forma parte de la tesis para optar al grado de Magister en Historia, mención en Historia de Chile, de la Universidad de Santiago de Chile. La investigación ha sido patrocinada por el FONDECYT N¹130323: "Contexto Histórico y dinámicas políticas de la insurgencia armada en Chile, 1978-1994”, a cargo de Igor Goicovic. Email jreyesoriano@gmail.com
} 
financiero generalizó el descontento ciudadano que provocó movilizaciones masivas contra la dictadura de Augusto Pinochet, las que repercutieron ostensiblemente en las poblaciones de Santiago. La reacción social significó, no obstante, que el régimen agudizará sus prácticas represivas: desde la primera manifestación opositora del 11 de mayo de 1983 hasta la última del 7 de octubre de 1987, período que además hubo tomas de terrenos, manifestaciones estudiantiles y marchas poblacionales, murieron 117 personas por agentes estatales. ${ }^{1}$

Aun cuando la violencia de Estado fue una tendencia inconmensurable a lo largo de la administración militar (1973-1990), ésta también obtuvo respuesta por parte de la izquierda armada y por sectores populares, especialmente capas juveniles, que a través de su experiencia e iniciativa se organizaron para dar una mínima respuesta a la arbitrariedad del Estado. Las organizaciones insurgentes (Movimiento de Izquierda Revolucionaria, MIR, Frente Patriótico Manuel Rodríguez, FPMR, y el MAPU-Lautaro) entre 1979 y 1990 fueron responsables de 77 bajas a miembros de las Fuerzas Armadas (FF.AA), Carabineros y agentes de inteligencia, aunque la mayoría de ellos (44) perecieron entre 1983 y $1987 .^{2}$ En otras palabras, la violencia política fue un rasgo distintivo en la sociedad chilena a partir del golpe de Estado, en la cual se conjugaron dos fenómenos bien marcados: la derrota del enemigo interno y la lucha contra el gobierno de facto. Sin embargo, y tomando como referencia lo expuesto por Igor Goicovic, el ciclo de violencia política se agudizó hacia 1978 , adquiriendo relevancia entre 1983 y $1987 .^{3}$

Una de las organizaciones de izquierda que enfrentó a la dictadura en toda la línea fue el Partido Comunista de Chile (PCCh), materializándose en la Política de Rebelión Popular de Masas (PRPM). Cuando se emprendió esta noción política con el discurso del Secretario General Luis Corvalán el 3 de septiembre de 1980 en Moscú, parte de su militancia se volcó al trabajo militar, tanto en factores teóricos como prácticos, surgiendo diversas alternativas para consolidar una estructura militar partidaria y cómo ésta se relacionaría con las masas, pensamiento que no cambió un ápice con la PRPM y el desarrollo de todas las formas de lucha, incluyendo "la violencia más aguda". Aquella estructura abarcó la creación de la fuerza militar propia, la lucha paramilitar de las masas y la realización de un trabajo ideológico hacia los cuerpos policiales y castrenses.

Ya cuando las movilizaciones opositoras eran un hecho la violencia estatal no se hizo esperar, por lo que desde la mirada comunista era prioritaria la organización de la autodefensa de masas. Se indicaban que frente al yugo de la "tiranía" las organizaciones sociales debían afianzar "un movimiento nacional de autodefensa de masas". Sólo así se lograrían evitar los crímenes perpetrados por uniformados y, a su vez, se preservaría "la

\footnotetext{
${ }^{1}$ Raúl Rettig (Coord.), Informe de la Comisión Nacional de Verdad y Reconciliación, Santiago, Andros Impresores, 1996, 1085-1112

${ }^{2}$ Ibid., 1026, 1051-1067.

${ }^{3}$ Igor Goicovic, "Temas y debates en la historia de la violencia política en Chile", Contenciosa, 3, Santa Fe, 2014, 4. Sobre el ciclo de protestas populares contra la dictadura militar puede consultarse Gonzalo de la Maza y Mario Garcés, La explosión de las mayorías. Protesta nacional, 1983-1984, Santiago, ECO, 1988; Gabriel Salazar, Violencia política popular en las “Grandes Alamedas”. Santiago de Chile 1947-1987. (Una perspectiva histórico-popular), Santiago, LOM Ediciones, 2006, 295-308.
} 
vida y la libertad de todos los que luchan por la democracia y, en definitiva, de proteger la seguridad de los chilenos".

Por otro lado, en la segunda mitad de la década algunas publicaciones clandestinas hicieron permanentes llamados a construir Milicias Rodriguistas (MR) en escuelas, fábricas y poblaciones para detener la represión y dar certeros golpes a ésta. ${ }^{5}$ Complementando lo anterior, textos favorables a la dictadura militar dieron cuenta que integrantes de las MR eran responsables de lanzar bombas incendiarias contra la locomoción colectiva en Pudahuel, de atacar a uniformados en la misma comuna en el marco del paro nacional del 30 de octubre de 1984, de colocar artefactos explosivos en distintos terminales de buses y de rociar con ácido un vehículo policial en Pudahuel en 1986, dejando heridos a sus ocupantes con quemaduras de diversa consideración. ${ }^{6}$ El Mercurio, mientras tanto, cada cierto tiempo en sus crónicas detalló el arresto de "subversivos" o "terroristas" que declararon ser parte de las MR. ${ }^{7}$ Asimismo, la Central Nacional de Informaciones (CNI) no dudó en interrogar y torturar a personas en el Cuartel Borgoño en busca de presuntos jefes de las MR. ${ }^{8}$ Por último, Sergio Buschmann, uno de los responsables de ingresar armas por Carrizal Bajo, refiriéndose a las MR señaló:

¿Quién en Chile no ha visto niños de catorce, quince años, con qué fuerza actúan en las protestas? Desde catorce hasta una edad ilimitada. Tenemos el trabajo de la Milicia Rodriguista sectorial. ¿Es una mentira que poblaciones en la noche son controladas por la Milicia? Todos las han visto, todos saben que es así. Pregúnteles a los señores Carabineros, si se meten a determinadas poblaciones. Pregunte por qué no se meten después de las 8 de la noche y qué es lo que ven cuando miran en las poblaciones para dentro. Quienes patrullan aquella población y cuidan aquella población. Esas son las Milicias, el primer camino que encuentra la juventud, de comprensión, de acercamiento al Frente Patriótico Manuel Rodríguez. ${ }^{9}$

A partir de las citas recién expuestas, nos preguntamos, ¿Qué era la autodefensa de masas y qué rol cumplía las MR en esta materia? Con esta interrogante el siguiente trabajo tiene por objetivo analizar, describir e interpretar la estructura paramilitar que fomentó el PCCh en los años que desplegó la PRPM. Estimamos que el análisis de este fenómeno no se entendería sin mencionar cómo en Chile se afianzó la Comisión Militar y el origen del FPMR en 1983. En función de lo anterior, daremos cuenta de los Comités de Autodefensa de Masas (CAM) y de las MR, donde los primeros se extendieron a lo largo de la década en

\footnotetext{
4 “Hacia un septiembre de grandes jornadas de movilización”, Boletín del Exterior, $\mathrm{N}^{\circ}$ 86, septiembre-octubre de 1987, 14.

5 "FPMR: dos años de combate", El Rodriguista, No 11, diciembre de 1985, 22; Frente Patriótico Manuel Rodríguez, "Paro nacional para echar a Pinochet", Arturo Lozza, Chile sublevado. Reportaje al FPMR, Buenos Aires, Editorial ANTARCA, 1986, 67.

${ }^{6}$ Pedro Varas, Chile: objetivo del terrorismo, Santiago, Instituto Geográfico Militar, 1988, 133, 137, 140, 147.

7 "Hallan refugio extremista y depósitos de explosivos", El Mercurio, 5-9-1986, C-7; "81 detenidos por los servicios de seguridad, El Mercurio, 8-10-1986, C-2.

${ }^{8}$ Vicaría de la Solidaridad, Informe Mensual, julio de 1986, 119.

9 "Testimonio de un combatiente. Entrevista con un dirigente del FPMR", Araucaria de Chile, № 41, 1988, 41.
} 
las organizaciones populares, mientras que finalizando 1984 irrumpieron en el escenario santiaguino poblacional las MR. Éstas últimas, a diferencia de los CAM, manejaron mayor cantidad de armamento y lograron consolidar una organización estable, aunque el número de potenciales milicianos aumentaba cuantiosamente para los días de protesta. Además, estimamos que las MR tampoco se entenderían sin hacer mención al proyecto políticomilitar de la Sublevación Nacional, tesis que apuntaba a la insurrección como mecanismo para acabar con la dictadura y su institucionalidad. Nos hemos concentrado en el ciclo 1982-1987 por dos factores: en primer lugar, en 1982 logró afianzarse la Comisión Militar en el país, lo que significó que el trabajo militar por parte de los comunistas chilenos adquiría incidencia directa en la lucha social; en segundo lugar, hacia 1987 las movilizaciones populares estaban en retroceso, coincidiendo con el desgaste de la salida insurreccional y la fractura entre el partido y el FPMR, por lo que el trabajo miliciano fue decantando y siendo menos notoria su relevancia. Con el fin de comprender qué era la autodefensa de masas y las MR, acudimos a documentos internos de la organización, entrevistas, testimonios de la época y prensa partidaria. Tanto las fuentes escritas como las orales nos permitieron reconstruir la consolidación de las MR, el armamento usado, las dinámicas del combate callejero, su auge y decadencia.

La historiografía y las ciencias sociales que abordan la experiencia del PCCh durante 1973-1990, han concentrado sus esfuerzos en discutir la PRPM y el nacimiento del FPMR. Sobre la primera, se definieron cuáles eran sus premisas, los debates teóricos, las discrepancias internas, la metamorfosis que vivió la militancia comunista en su cultura política y qué consecuencias trajo hacia la colectividad al finalizar el gobierno de facto. ${ }^{10}$ En referencia a la segunda, se ha dado cuenta sobre la genealogía de sus comandantes, el accionar armado de los rodriguistas, el ingreso de armas por Carrizal Bajo, el atentado hacia la comitiva del dictador, la separación del PCCh por las diferencias ideológicas en torno al uso de las armas y su vida autónoma en los primeros años de transición democrática. $^{11}$

${ }^{10}$ Rolando Álvarez, Desde las sombras. Una historia de la clandestinidad comunista (1973-1980), Santiago,
LOM Ediciones, 2003; Rolando Álvarez, Arriba los pobres del mundo. Cultura e identidad política del
Partido Comunista de Chile entre democracia y dictadura. 1965-1990, Santiago, LOM Ediciones, 2011;
Viviana Bravo, Con la razón y la fuerza venceremos. La Rebelión Popular y la subjetividad comunista en los
'80, Santiago, Ariadna Ediciones, 2010; César Quiroz, "La política de rebelión popular de masas", Manuel
Loyola y Jorge Rojas, Por un rojo amanecer. Hacia una historia de los comunistas chilenos, Santiago,
Impresora Valus, 2000, 247-275; Tomás Moulian e Isabel Torres, "Continuidad o cambio en la línea política
del Partido Comunista de Chile”, Augusto Varas (Comp.), El Partido Comunista de Chile: estudio
multidisciplinario, Santiago, FLACSO-CESOC, 1988, 453-485; Tomás Moulian, Chile actual: anatomía de
un mito, Santiago, LOM Ediciones-ARCIS, 1997, 264-269, 328-336; Alfredo Riquelme, Rojo atardecer. El
comunismo chileno entre dictadura y democracia, Santiago, Centro de Investigaciones Diego Barros Arana,
2009; Augusto Samaniego, "Lo militar en la política: lectura sobre el cambio estratégico en el PC. Chile,
1973-1983", Revista de Historia y Ciencias Sociales Palimpsesto, 1:1, Santiago, 2004, 1-23; Augusto Varas,
"De la violencia aguda al registro electoral: estrategia y política de alianzas del PC, 1980-1987”, Documentos
de Trabajo FLACSO, 362, Santiago, 1987, 1-36; Hernán Venegas, "Trayectoria del Partido Comunista de
Chile. De la crisis de la Unidad Popular a la Política de Rebelión Popular de Masas, Revista Universum, $24: 2$,
Talca, 2005, 262-293.
11 Álvarez, Arriba los pobres...op. cit. 193-253; Rolando Álvarez, "Los hermanos Rodriguistas. La división
del Frente Patriótico Manuel Rodríguez y el nacimiento de una nueva cultura política en la izquierda chilena.
1975-1987, Revista Izquierdas, 3:2, Santiago, 2009, 1-9; Rolando Álvarez, "El Frente Patriótico Manuel
Rodríguez: génesis y desarrollo de la experiencia de la lucha armada del Partido Comunista contra la 
Los estudios que han puesto a la palestra el trabajo militar que ejecutó el PCCh en los ochenta apuntan a similares tópicos. Tanto Viviana Bravo, Rolando Álvarez y Luis Rojas mencionan el nacimiento de la Comisión Militar, compuesta por la Fuerza Militar Propia (FPMR), el Trabajo Militar de Masas (TMM) y el Trabajo Hacia el Ejército (THE). Específicamente sobre el TMM, punto al que intentamos acercarnos en este artículo, nació para adicionarse a la estructura territorial clásica del partido que no había cambiado con el quiebre institucional de 1973. Es así como los Secretarios Regionales y Locales debían tener subordinado a un encargado militar, siendo el responsable de administrar las tareas de sabotajes y "debía tratar de incorporar e influir en las mayorías populares no militantes, a luchar contra la dictadura empelando formas paramilitares de enfrentamiento". ${ }^{12}$ En 1984 debutaron las MR, surgidas por las experiencias de las protestas sociales del bienio 19831984 y por el prestigio adquirido del FPMR, realizando acciones en las universidades, liceos y poblaciones. ${ }^{13}$ También se subraya que los milicianos provenían de las Juventudes Comunistas (JJCC), que a consecuencia de la PRPM también militarizó parte de su estructura interna y formó cuadros orientados hacia la autodefensa. ${ }^{14}$ Álvarez, puntualmente, ha destacado cómo los CAM lograron ser notoriamente visibles en la enseñanza media al organizar las manifestaciones, tomarse los liceos y constituir grupos de choque para enfrentarse a la policía. ${ }^{15}$

En resumen, y haciendo un balance en cuanto al estado del arte, se aprecia que el tema de la autodefensa de masas y las MR no han gozado de la atención necesaria, tanto en los respectivos libros como en las monografías antes citadas. Se colige que las investigaciones en torno a la autodefensa y las MR son secundarias, casi marginales del proceso, paradojalmente cuando la mayor apuesta del partido era que las masas ejercieran todas las formas de lucha, incluyendo la actividad paramilitar. Estimamos que es relevante comprender la experiencia miliciana, pues en ese espacio se lograba consolidar el trabajo partidario y el desarrollo de la violencia política por parte de las masas. Es decir, la autodefensa y las MR reflejaron el encuentro entre la tradición del partido con nuevas formas de lucha, adaptadas al escenario de la dictadura de Augusto Pinochet.

dictadura de Pinochet", Taller (segunda época), 2:2, Bueno Aires, 2013, 49-61; Bravo, op. cit., 60-80, 93-95; Igor Goicovic, "Transición y violencia política en Chile (1988-1994), Ayer, 79:3, Madrid, 2010, 59-86; Luis Martínez, "Lo Militar y el FPMR en la Política de Rebelión Popular de Masas: orígenes y desarrollo", Alternativa, 23, Santiago, 2005, 68-82; Claudio Pérez, "Violencia y política en las publicaciones clandestinas bajo Pinochet: la palabra armada en el Frente Patriótico Manuel Rodríguez. Chile, 1983-1987", Revista Historia Social y de las Mentalidades, 12:2, Santiago, 2008, 71-90; Claudio Pérez, "De la guerra contra Somoza a la guerra contra Pinochet. La experiencia internacionalista revolucionaria en Nicaragua y la construcción de la fuerza militar propia del Partido Comunista de Chile”, Pablo Pozzi y Claudio Pérez (Eds.), Historia oral e historia política: izquierda y lucha armada en América Latina, 1960-1990, Santiago, LOM Ediciones, 2012, 213-244; Luis Rojas, De la rebelión popular a la sublevación imaginada. Antecedentes de la historia política y militar del Partido Comunista de Chile y del FPMR, 1973-1990, Santiago, LOM Ediciones, 2011; Pedro Rosas, Rebeldía, subversión y prisión política: crimen y castigo en la transición chilena, 19902004, Santiago, LOM Ediciones, 2004, 79-84, 128-136; Hernán Vidal, Frente Patriótico Manuel Rodríguez. El tabú del conflicto armado en Chile, Santiago, Mosquito Editores, 1995.

${ }^{12}$ Rojas, op. cit., 24.

${ }_{13}^{13}$ Álvarez, Arriba los pobres...op. cit., 229-230.

${ }^{14}$ Bravo, op. cit., 222-223.

${ }^{15}$ Rolando Álvarez, "El movimiento estudiantil secundario bajo dictaduras y las juventudes comunistas: un caso de radicalización política de masas" Alternativa, 23, Santiago, 2005, 83-114. 
Para una mejor comprensión del tema, es necesario hacer referencia a la categoría de violencia política. Julio Aróstegui estipuló que la violencia es una forma de relación social, expresada desde las interacciones personales hasta cuestiones políticas asociadas al poder. ${ }^{16}$ Es así como la violencia en la política es el accionar de un colectivo que busca controlar el funcionamiento de un sistema político para así ejercer su dominio. ${ }^{17}$ Bajo este supuesto, la mayoría de los Estados contemporáneos lograron construir leyes e instituciones a causa de una acción violenta: revolución, golpe de Estado o una derrota militar frente a una potencia extranjera. Fue común durante el siglo XX que ideologías y organizaciones políticas incluyeran un elemento de fuerza en su praxis cotidiana. ${ }^{18}$ Particularmente en Latinoamérica, a mediados de los cincuenta explotaron los ciclos de violencia política relacionados a una época de cambio: migraciones del campo a la ciudad, demandas por tierras, la consolidación de la clase obrera y el proceso de politización vivida por numerosos grupos sociales que apostaban por un cambio en la estructura económico-social, ya sea por vía democrática o por medio de las armas. Lo anterior desembocó en una reacción oligárquica que, junto al beneplácito norteamericano, impulsó regímenes autoritarios o democracias restringidas. Fue así como en el continente se esparcieron las guerrillas revolucionarias, que fueron derrotadas rápidamente para dar paso a sanguinarias intervenciones militares en un alto número de países. ${ }^{19}$

En Chile, la dictadura militar expresó la manifestación superior de violencia ejercida hacia organizaciones de izquierda y el mundo popular en su conjunto. Esta situación provocó cambios en el PCCh, los cuales se agudizaron con la Constitución de 1980. Lo anterior llevó al partido a definir nuevas formas de lucha, en la cual se incluía la "violencia aguda". Ante esto, entendemos que "la violencia es constitutiva de la práctica política porque es fundadora de juricidad estatal". ${ }^{20}$ Por medio de la lucha política y más acciones de violencia, los comunistas teorizaron que una vez expulsado Pinochet del poder se convocaría una asamblea constituyente y un gobierno de transición, estableciendo una nueva institución y régimen social en el país. A partir de la deslegitimación del nuevo orden jurídico, los comunistas apelaron al uso de la violencia con las masas, militarizó algunos cuadros e impulsó sabotajes a nivel nacional. Este comportamiento, a juicio de Santos Juliá, responde a que los ciclos de violencia política son más agudos cuando nacen de la ciudadanía y organizaciones políticas consideran que la institucionalidad es ilegítima, poniendo en práctica el boicot y la toma de las armas. ${ }^{21}$

Estimamos que en los CAM se cruzaron dos variables a lo largo de las jornadas de movilización opositoras: en primer lugar, un número importante de pobladores se coordinaban para enfrentar a la dictadura de forma instintiva, aunque no hay indicios que la organización traspasara la frontera de la protesta; por otra parte, el partido consciente que estas acciones eran la clara muestra de cómo las masas desafiaban al régimen, apelaba a

\footnotetext{
${ }^{16}$ Julio Aróstegui, "La violencia política y su dimensión histórica", Antonio Rivera y Carlos Carncero (Eds.), Violencia política. Historia, memorias, víctimas, Madrid, Maia Ediciones, 2010, 23-31.

${ }^{17}$ Julio Aróstegui, "Violencia, sociedad y política: la definición de la violencia”, Ayer, 13:1, Madrid, 1994, 17-55.

${ }^{18}$ Philippe Braud, Violencias políticas, Madrid, Alianza Editorial, 2006, 42-79.

${ }^{19}$ Pablo Pozzi y Claudio Pérez, (Eds.), Historia oral e historia política... op . cit.

${ }^{20}$ Eduardo Grüner, Las formas de la espada. Miseria de la teoría política de la violencia, Buenos Aires, Ediciones Coligue, 2007, 31-32.

${ }^{21}$ Santos Juliá, (Ed.), Violencia Política en la España del siglo XX, Madrid, Taurus, 2000, 13-22.
} 
promover un trabajo paramilitar más estable y constituido. Consideramos que la reciprocidad entre la experiencia popular de resistir a las fuerzas represivas y el trabajo militar del partido a nivel local dieron paso a las MR, agrupación paramilitar de masas cualitativamente superior. Lo importante de éstas es que tuvieron acceso a armamento de bajo calibre y especialmente casero; asimismo, con las milicias hubo una racionalización del combate callejero con tácticas de ataque, defensa, pertrechos y labores conspirativas. Las MR evidenciaron un contacto entre el partido, la célula y el FPMR, ya que de esta triada se forjaron cuadros que transitaron del partido al brazo armado, y éste último tuvo incidencia en el actuar de las milicias en las poblaciones. A su vez, las MR muestran los cambios al interior de la militancia comunista de base, donde las tareas paramilitares lograron un importante arraigo expresados en los cortes de luz por derribamiento de postes, el manejo de armamento hechizo y el uso de bombas caseras contra la policía. Por último, el surgimiento de las MR no significó el fin de los CAM, ya que estos siguieron operando en los recintos de enseñanza media y poblaciones.

\section{Nacimiento de la estructura militar del Partido Comunista de Chile, 1980-1983}

La revista Principios en diciembre de 1981 publicó un artículo en referencia directa a la necesidad de discutir sobre lo militar en la actividad política. Se planteó que lo militar estaba asociado directamente al tránsito del pueblo al poder y su consolidación, por lo que debía ser concebido como parte sustancial de la línea partidaria. Que un texto editado por la revista teórica del partido hablase sin tapujos del factor militar demostraba que las posturas discrepantes frente al tema ya tenían un curso mínimo de acción y una propuesta concreta en el escenario chileno. Lo señalado en este documento fue por lo que se jugó la colectividad comunista en los años ochenta: buscar una correlación de fuerzas favorables a la lucha para derrocar a Pinochet y conquistar la democracia. El texto puntualizaba que hubo dos formas de zanjar una correlación militar favorable: la primera, es que una parte del antiguo Ejército pasara al bando revolucionario como fue el caso ruso en 1917 y portugués en 1974; y la segunda, más común en los procesos revolucionarios, era que la correlación militar a favor del pueblo floreció cuando las propias masas la construyeron. Por ende, tomando en cuenta el rol que cumplían las FF.AA y de Orden, se afirmó que la segunda propuesta era la más viable en el país, esperando que a ella se sumaran militares y policías con tendencias democráticas. ${ }^{22}$

Fue así como se profundizó lo propuesto por el Comité Central en mayo de 1981, donde someramente se había destacado la incipiente estructura militar: la Fuerza Militar Propia, la Organización Paramilitar de las Masas y el Paso de una parte de las FF.AA. y de Orden a la correlación militar del pueblo. En cuanto a la primera, ésta transitaría por las distintas etapas de la rebelión popular, dependiendo de la agudización de la lucha de clases y de los alcances concretos que alcanzará la política impulsada por el PCCh. En una primera etapa actuaba sólo de manera operativa, destacando entre ella actividades de propaganda y agitación. Ya en un grado superior, el grupo operativo realizaba acciones de mayor envergadura: paralizar, debilitar y aniquilar al enemigo. Cuando la rebelión llegase a

\footnotetext{
${ }^{22}$ Camilo González, “Lo militar en la política del Partido”, Principios, № 22, enero-febrero de 1982, 36-37.
} 
su maduración completa, pasaría a un estado superior: "la fuerza militar propia de la revolución". En este grado actuaba como una organización independiente con el fin de devastar al bando enemigo, sumándose a ella fuerzas aliadas, aunque "siempre bajo la dirección político-militar del partido de vanguardia". ${ }^{23}$

En lo concerniente a la organización paramilitar de masas, era teorizado como uno de los componentes naturales y más importantes de la lucha de masas, prevaleciendo en los recintos de trabajo, estudio y en las grandes poblaciones populares. Era imperioso consolidar organizaciones de masas de nuevo tipo, que incorporasen los actos de violencia en el repertorio de la protesta social. La organización paramilitar de masas eran "los organismos privilegiados para la desobediencia y resistencia civil al fascismo, para la agitación y la propaganda, para la autodefensa de sus movimientos reivindicativos y políticos, así como para las ofensivas más masivas, multitudinarias del pueblo". ${ }^{24}$

Con el fin de lograr una correlación de fuerza militar favorable al pueblo, era prioritario que una parte de las FF.AA. y de Orden se sumaran a la lucha "antifascista". La propuesta del partido era que el sector democrático al interior de los cuerpos castrenses y policiales conquistase a sus pares, sumándolos a la lucha armada contra el régimen. Por lo tanto, la tarea de los comunistas en esta área era distribuir propaganda política en los lugares del país donde hubiese recintos militares y policiales. ${ }^{25}$

Los dirigentes comunistas en Chile, agrupados en el Equipo de Dirección Interior (EDI), reclamaron que había un importante retraso en el terreno militar, criticando que no se aprovechaban las condiciones objetivas (crisis económica, descomposición moral, aislamiento internacional) para dar un golpe certero a Pinochet. Para superar estas falencias, se debía implantar una estrategia política y una militar: la primera consistía en denunciar la arbitrariedad de la administración castrense, sus crímenes y modelo económico, por medio de la desestabilización, marchas, acciones audaces, etc.; en el segundo punto, los comunistas debían enfocarse de lleno a estudiar el carácter de la lucha armada, cuáles eran las fuerzas enemigas, cómo reaccionaría el imperialismo norteamericano y comprender las formas más eficaces para enfrentar al enemigo: guerrilla, lucha política con acciones armadas, insurrección, etc. El EDI sostuvo que era una obligación de todo el partido sumarse a las tareas de desestabilización, junto con las masas y no en un frente especializado, por lo que era prioritario que los Comités Locales y Regionales asumieran las distintas tareas que exigía la rebelión. El EDI sentenció: "Tenemos la obligación de ganar ideológicamente el partido, al relacionar muy bien el desarrollo de la lucha política con formas de lucha armada". ${ }^{26}$

Como es posible de observar, una de las cuestiones que más revuelo tuvo en el seno de la colectividad comunista fue establecer una estructura militar. Antes del Golpe de Estado funcionaron las Comisiones de Vigilancia y los Grupos Chicos, enfocados en la defensa de dirigentes y locales partidarios. Luego que la dictadura se impusiera el PCCh optó por formar Comisiones Militares, que funcionaron en Cuba desde 1977 y otra en la

\footnotetext{
${ }^{23}$ Ibid., 37-38. Los subrayados en el original.

${ }^{24}$ Ibid., 40.

25 Ibid., 41.

26 "La crisis y las condiciones objetivas. Documento editado por el Equipo de la Dirección Interior", en Partido Comunista de Chile, Rebelión popular, camino de la victoria, Editado Clandestinamente, Santiago, $1982,58$.
} 
República Democrática Alemana a partir de 1978. Sin embargo, la más significativa fue la Comisión Militar que se radicó en Chile hacia fines de 1981 e inicios de 1982, a cargo de Guillermo Tellier hasta culminar $1986 .{ }^{27}$ No obstante, la consolidación de ésta no estuvo ausente de embrollos, diferencias y complejidades que atravesaron al partido a lo largo de estos años. Guillermo Tellier señala que el EDI apelaba por incorporar al país a los oficiales que habían participado en la revolución nicaragüense de 1979, pues su experiencia militar sería un aporte fundamental en la lucha por el retorno a la democracia. Fue así como el EDI logró romper con la idea inicial acerca de los oficiales comunistas formados en diferentes academias de guerra en países socialistas desde 1975, pues se creyó éstos darían vida al nuevo Ejército chileno luego de la caída de la dictadura. ${ }^{28}$

La concepción de sumar cuadros especializados a Chile no era monopolio del interior, pues desde Cuba los oficiales graduados también presionaban por reingresar al país. César Quiroz, antiguo combatiente rodriguista formado en Bulgaria, recuerda que el año 1982 fue particularmente crítico en el aparato militar del partido radicado en la isla caribeña. El origen del conflicto se remitía a la poca claridad con el número importante de cuadros militares formados, pues estaban reunidos los oficiales graduados de Cuba, Bulgaria y los que volvían de la experiencia nicaragüense. Las diferencias se manifestaron entre Jacinto Nazal y Galvarino Apablaza: el primero reflejaba las posturas que eran compartidas por los dirigentes que estaban arraigados en Europa Oriental, de no permitir el ingreso de los oficiales a Chile; mientras que Apablaza representaba la opinión mayoritaria de los oficiales comunistas, de "acelerar el proceso de rebelión de masas, con incorporación de formas agudas, que para nosotros era meterle con los fierros. Después de Nicaragua, teníamos muy claro que lo que aquí cabía era meterle con todo". " ${ }^{29}$ El partido ante este escenario optó por enviar nuevamente oficiales a Nicaragua para enfrentarse a la "Contra", que intentaba obstaculizar el proceso revolucionario financiada por la CIA, y, al mismo tiempo, permitió el ingreso de militares comunistas a Chile a mediados de 1983, encabezados por Raúl Pellegrini.

Otra discrepancia era si el partido debía sumarse por completo a la actividad militar o sólo una parte de él. El EDI esbozaba que toda la colectividad debía participar en las tareas militares, mientras que desde el exterior, como Jorge Montes, apostaban a que se formara un equipo de elite para que operase y luego se marchara de Chile, evitando así que a la colectividad se le acusara de acción ilícita. Ante esta disyuntiva, Guillermo Tellier recuerda:

O el partido se transformaba en un destacamento para todas las formas de lucha o conformábamos un destacamento separado del partido. Se optó por lo último, no diré con el acuerdo de todo el partido, porque había compañeros que reparaban más en los peligros involucrados en la creación de este tipo de movimientos para desarrollar la lucha, que en ver cómo colaborar y cómo sacar las cosas para adelante. Se acordó entonces formar el Frente Patriótico Manuel Rodríguez. Este destacamento lo conformamos con oficiales que venían de afuera y compañeros del interior,

\footnotetext{
${ }^{27}$ Bravo, op. cit., 129; Rojas, op. cit., 22. Sobre las Comisiones de Vigilancia y Grupos Chicos, Álvarez, Arriba los pobres...op. cit., 57.

${ }^{28}$ Guillermo Tellier, en Francisco Herreros, Del gobierno del pueblo a la rebelión popular, Santiago, Ediciones Siglo XXI, 2003, 508.

${ }^{29}$ El testimonio de César Quiroz, en ibid., 513-514.
} 
supeditado a la Comisión Militar del partido. Elegimos el nombre de Manuel Rodríguez por lo que significó para la independencia de Chile. Se acuñó el término rodriguismo, se empezaron a formar cuadros en Chile, y también a prepararlos en el exterior, se formaron destacamentos a través de todo el país. ${ }^{30}$

Con el arribo de los oficiales comunistas a mediados de 1983 se dieron los primeros pasos para consolidar definitivamente la estructura militar con profesionales en el tema. Dos combatientes internacionalistas se sumaron a la Comisión Militar: Raúl Pellegrini, Comandante José Miguel, a cargo del FPMR y Galvarino Apablaza, Comandante Salvador, responsable del TMM. ${ }^{31}$ Cuando Pellegrini ingresó al país fue recibido por Oscar Riquelme, quien era el encargado militar del partido en Chile antes de la Comisión Militar, el cual presentó a los jefes de la naciente fuerza militar que ya operaba. Antes del nacimiento del FPMR la estructura militar estaba organizada en Santiago, Valparaíso y Concepción, actuando en Grupos Operativos integrados por militantes de la juventud y del partido. También hubo una logística distribuida en las tres capitales regionales, con sus respectivos barretines y armamentos. En cuanto al trabajo militar destinado hacia las masas sólo tuvo mayor revuelo en los regionales más importantes, donde se constituyeron Unidades de Combate en la lucha territorial, aunque de forma inestable y con precarios recursos, claramente insuficientes para enfrentar las jornadas de movilización popular que estaban desarrollándose desde mayo de $1983 .{ }^{32}$

El partido por más que haya emplazado a la rebelión en septiembre de 1980 mostró claras falencias para establecer una estructura militar, principalmente por las renuencias de sectores que estaban en el exterior. Se desprende, en consecuencia, que los esfuerzos consumados durante 1983 fue instaurar un aparato militar adaptado a la realidad nacional convulsionada desde mayo, evidenciando que los antiguos Grupos Operativos no eran capaces de dar golpes más certeros a la dictadura. Ya con los oficiales en Chile se conformaron pequeños destacamentos que cometieron los primeros actos de propaganda para hacer pública la organización, pero sólo con el apagón nacional del 14 de diciembre de 1983 se logró aquel objetivo. El transitó para constituir la fuerza militar propia fue complejo, pero ya era un hecho que sorprendería a los aparatos de seguridad como al mismo partido. Sin embargo, ¿qué ocurría con el trabajo paramilitar de masas y cuáles eran sus avances en estos años?

\section{Entre el aprendizaje y la consolidación: los Comités de Autodefensa de Masas}

Aunque desde 1981 había grupos destinados al TMM, no existía una concepción clara en cuanto a las tareas asignadas. Como lo notifica Rojas en su estudio, el TMM no tuvo una fecha de origen determinada, consolidándose a fines de 1983 e inicios de 1984.

\footnotetext{
${ }^{30}$ Guillermo Tellier, en ibid., 509.

${ }^{31}$ Pérez, "De la guerra contra Somoza", op . cit., 240.

${ }^{32}$ Rojas, op. cit., 231.
} 
Los responsables del TMM recibían indicaciones de especialistas militares de nivel superior y los "combatientes" eran militantes del partido y la juventud. ${ }^{33}$

Hacia 1982 los comunistas estaban conscientes que un elemento fundamental para derrotar a Pinochet era que las fuerzas democráticas fueran activos en el terreno paramilitar. La lucha contra la represión era la "autodefensa popular de masas", lo cual se tradujo en afianzar una estructura apropiada que fuera capaz de responder el actuar del aparato policial y proteger las actividades reivindicativas. El rol de la autodefensa de masas era ejercer operaciones de fuerza para inhibir a la represión y sus colaboradores, especialmente con los soplones mediante rayados, amenazas y amedrentamientos. Por último, la autodefensa no era ejercida por grupos de especialistas, sino que se apostó por la masividad y la participación más amplia. ${ }^{34}$

Desde 1982 las publicaciones partidarias mencionaron que en las poblaciones como en los sindicatos florecieron los CAM para resguardar a los dirigentes, enfrentar a la policía y rescatar a los detenidos. Ramón Vargas, militante comunista hasta la actualidad, en 1982 era el encargado del Comité Regional Norte de Santiago. Recordando qué eran los CAM, asegura que estos nacieron en las células de las poblaciones con gran desarrollo y en algunas actuaban abiertamente: "Por ejemplo, las experiencias que nosotros recogíamos, que se transmitían, es que los comités cerraban la población a través de barricadas para que los milicos o carabineros no pudieran entrar, y en eso participaba la población entera". ${ }^{35}$

Luego de la primera protesta del 11 de mayo de 1983, el partido redactó una declaración pública haciendo un vehemente llamado "a derrotar la represión, instrumento fundamental del dominio de Pinochet, a inhibirla y sobrepasarla, organizando comités de autodefensa, resistiendo los allanamientos, impidiendo las detenciones, realizando acciones ejemplares contra los agentes y colaboradores del aparato represivo". ${ }^{36}$ Marcelo al respecto complementa:

Los comités surgen en algunos sectores, en los más radicalizados, y tenían la función de darle cierta orgánica a la pelea callejera, porque inicialmente era ataque de indios: todos íbamos, nos concentrábamos en un punto, resistíamos y después era un desbande, todos arrancábamos. Los comités de autodefensa tuvieron tareas más específicas: función de explorar, ver los puntos dónde se podía romper, cuáles son los puntos a defender. Otro comité se encargaba de sanidad, otro de pertrechamiento, grupos de contención, como que se especializaban ciertas cosas. ${ }^{37}$

Ya con el correr de las protestas se levantaban distintos comités, pero eran bastantes febles y precarios. Una de las primeras estimaciones que podemos destacar de la autodefensa de masas es que era focalizada en las poblaciones con tradición de lucha social

\footnotetext{
${ }^{33}$ ibid., 22-23.

34 "Por una salida popular", Principios, № 26, noviembre-diciembre de 1982, 16-17.

${ }^{35}$ Entrevista con Ramón Vargas, 15-07-2014.

36 “'Basta! ¡Democracia Ahora!”, Boletín del Exterior, № 59, mayo-junio de 1983, 20.

${ }^{37}$ Entrevista con Marcelo 27-11-2014. Antiguo militante comunista que ingresó a las JJCC en 1981, que luego de foguearse en lucha callejera se hizo cargo del TMM en su población, transitando por las MR, para luego engrosar las filas del FPMR; tras el quiebre con el PCCh optó por seguir el proyecto de Raúl Pellegrini. A petición del entrevistado se cita el nombre con el cual actuó en aquellos años.
} 
y donde el partido tuvo raíces remotas. La organización popular se complementó con la actividad partidaria, en que los militantes participaban enérgicamente en todo lo relativo a la vida poblacional de la época: ollas comunes, comprando juntos, comités de vivienda, peñas folclóricas, etc., siendo esos espacios de socialización en los cuales se desplegaron los primeros pasos de la PRPM. Por otra parte, la propia experiencia de los sectores populares, que sufrieron vejaciones y humillaciones policiales, los instaron a organizarse para enfrentar a la represión. Ejemplo de ello es el testimonio de Cristian, joven poblador de 21 años:

Los hechos de violencia más grandes se han producido por la aparición de Carabineros, que son los que producen la ira de la gente. Ha habido oportunidades en que se han hecho desfiles y marchas y no ha pasado nada, porque ellos no llegan. Pero cuando lo hacen se produce todo lo contrario del orden: se tiran piedras, se arman barricadas y hasta colchones se sacan para prender en la calle. Es la imagen de ellos la que violenta, porque el régimen se representa en el carabinero que viene con el palo o en un bus, y entonces se produce lo de la rebeldía y se descarga toda la rabia. Así es también cómo reacciona la fuerza pública. ${ }^{38}$

Según Cristian, la experiencia en su población era que cada vez que sus habitantes se mostraron pacíficos hubo un alto número de heridos; en cambio cuando los pobladores prepararon la defensa del territorio, con el levantamiento de barricadas en las calles y pasajes, "han sido mucho menos el apaleo y la cantidad de detenidos entre los pobladores". ${ }^{39}$ En rigor, la defensa de las poblaciones era feble, desorganizada y caótica. El párroco La Legua, Guido Peters, exponía que no había manera de hacer frente al actuar de la policía que bombardeaban las avenidas y endebles viviendas con balines y elementos lacrimógenos. A pesar que se alzaban barricadas y se sacaban las tapas del alcantarillado, no se logró dificultar el avance de tanquetas y buses con uniformados. Ya en el seno de La Legua Carabineros rompió vidrios, echó abajo las puertas de las casas, golpeó a sus moradores, destruyó habitaciones, techos y enseres domésticos. ${ }^{40}$

Los comunistas aseguraban que ante el actuar delictivo de las fuerzas coercitivas era imprescindible preparar y organizar la autodefensa. La colectividad orientaba "a defenderse de la CNI y a luchar activamente contra la CNI, contra los sapos y torturadores". El trasfondo era que las masas combatieran "en todos los terrenos y saber discernir cuándo debe emplear un método de combate y cuando otro, así como a combinar métodos". ${ }^{41}$ Lo concreto era que la autodefensa mejoraba lentamente, pero sin dar un salto importante hasta el momento, evidenciando más que todo improvisación e instinto. Pedro Soto, por ejemplo, da cuenta de cómo se vivía una protesta en el Callejón Lo Ovalle: "Vinieron los pacos a provocarnos, nos tiraron bombas lacrimógenas y luego empezaron a dispararnos. Ante tanta prepotencia, les hicimos frente y nos fuimos en collera. Los agarramos a peñascazos y a palos, les lanzamos de vuelta sus propias bombas y los hicimos arrancar". ${ }^{4}$

\footnotetext{
38 “Los estallidos de la ira", APSI, N 155, 29 de octubre al 11 de noviembre de 1984, 12.

${ }^{39}$ Idem.

40 "La violencia vino de un lado", Análisis, № 63, 30 de agosto al 13 de septiembre de 1983, 19.

41 "50 preguntas al partido", Boletín del Exterior, № 64, marzo-abril de 1984, 15.

42 "Rechazamos a los pacos", Boletín de Prensa El Siglo, No 24, 31 de marzo al 6 de abril de 1984, 2.
} 
Destacamos que los CAM gozaron de tareas asignadas y específicas como las de sanidad, propaganda y abastecimiento, aunque la idea principal era defenderse de la policía que ingresaba a las poblaciones. En Villa Portales los CAM fueron responsables de levantar "barricadas con 24 neumáticos y varios litros de bencina", en la "Avenida Sur con Sophora, Portales con General Velázquez, Avenida Norte con Sophora y Puente las Encinas". A las 21 horas ingresó Fuerzas Especiales con dificultad, disparando y dejando heridos a dos jóvenes, "pero luego son rechazados gracias a un apagón provocado en Pudahuel y a la organización de los pobladores en Comandos de Autodefensa". ${ }^{4}$

En La Victoria la situación era similar. En una jornada de movilización opositora "el Comité de Autodefensa empieza su actividad a las 6 de la mañana con 7 barricadas en el barrio, armadas con neumáticos y otros implementos, que ya se habían reunido". Luego de aislar la población, prohibiendo en ingreso de la locomoción colectiva e impidiendo que el comercio funcionara, se realizaban marchas y discursos políticos. Lo fundamental para los comunistas era resaltar que "la autodefensa es asumida plenamente por los pobladores que ayudan a la protección de quienes son perseguidos por la represión". ${ }^{44}$ Reflexionando de lo que ocurría generalmente en las poblaciones, se concluyó que la forma más común en lucha callejera era la implementación y desarrollo de la barricada, extendiéndose en avenidas principales en defensa del territorio. Es decir, la organización del partido se fusionaba con la voluntad de los pobladores de resistir, evidenciando que la experiencia popular de combate era un constante aprendizaje: "Aquí los pacos se habían acostumbrados a reprimir a diestra y siniestra. De ahí que levantamos la consigna de "Pudahuel Zona de Combate" y nos preparamos para resistir. Varias veces intentaron los pacos tomarse la población y no pudieron". ${ }^{45}$ El pasquín comunista felicitaba a los organismos de autodefensa por la creatividad y disposición al enfrentamiento. En una nota haciendo referencia a La Victoria detallaba:

Las barricadas y piquetes de autodefensa comenzaron a funcionar a las 4.30 de la madrugada del 30 de octubre. Aparte de la ayuda tradicional combatividad de que hacen gala los victorianos pusieron en práctica algunas iniciativas de tipo militar que les rindieron los frutos esperados. Con el objeto de impedir la entrada de pacos, microbuses policiales o tanquetas, los pobladores agrupados en los Comités de Autodefensa cavaron un total de 40 zanjas, lo que hizo exclamar a los oficiales: "Miren los huevones, como están afinando la pelea". Entrevistado por El Siglo, uno de los responsables del comité de defensa de población (CDP) afirmó que "vamos a ir afinando aún más nuestra defensa, con tal de impedir que las fuerzas represivas ingresen a la población". ${ }^{6}$

Las citas hasta ahora evidencian cómo germinaba el TMM en la primera mitad de la década, participando innumerables personas organizadas en distintas tareas y donde el partido sumaba a ellas. Aunque los CAM se extendieron a lo largo de la década, era una organización inestable que no lograba traspasar la barrera de las protestas, lo cual fue

\footnotetext{
43 "El ejemplo de Villa Portales", Boletín de Prensa El Siglo, № 49, 22 al 28 de septiembre de 1984, 6.

44 "Autodefensa en las poblaciones (palabras de un combatiente)", Basta, $\mathrm{N}^{\mathrm{o}}$ 47, septiembre de 1984, 5-6.

45 "Zona de combate", El Siglo, $\mathrm{N}^{\circ} 7595$, noviembre de 1984, 8.

46 "Miren los huevones como afinan la pelea", Boletín de Prensa El Siglo, N 55, 3 al 9 de noviembre de 1984,3 .
} 
superado gracias a la consolidación y crecimiento de las MR a partir de 1984. A pesar que la existencia de las milicias fue relativamente corta, sin embargo, mostró el aprendizaje por parte del partido y de los sujetos que sumaban para dar una resistencia eficaz a la embestida dictatorial, en que las experiencias de vida y el proyecto político comunista se conjugaban en los hechos de violencia cometidos por las masas populares.

\section{De la piedra al fusil: Las Milicias Rodriguistas, 1984-1987}

La primera característica de las $\mathrm{MR}$ es su origen difuso, pues surgió en las poblaciones en función al combate callejero que se desplegaba en los territorios, participando en ellas militantes comunistas como individuos sin colectividad política. No obstante, finalizando 1984 se empezó a tener cierta noción sobre ellas. El 16 de octubre de aquel año el FPMR realizó 40 bombazos a entidades bancarias a lo largo del país y a las 22:00 horas destacamentos especializados derribaron 15 torres de alta tensión, provocando un apagón generalizado entre Copiapó y Temuco. En un comunicado de prensa el FPMR se adjudicaba los atentados, asegurando que los hechos eran "una primera demostración de lo que será la nueva fase de nuestra campaña, la que se verá multiplicada por la actuación de las Milicias Rodriguistas". ${ }^{47}$ El 19 de diciembre de 1984, en pleno Estado de Sitio, el FPMR en un acto de propaganda secuestró al subdirector del diario La Nación, Sebastiano Bertlone Galleti, siendo liberado 6 días después en los alrededores de la población La Victoria. En esta acción se dio a conocer el primer Manifiesto Rodriguista, el cual, además de reivindicar la violencia revolucionaria y la toma de las armas ante la brutalidad de la dictadura, fomentaba la creación en cada lugar y zona de las "Milicias Rodriguistas, órgano de combate auténticamente popular que tendrá a su cargo la organización y desarrollo de la capacidad combativa del pueblo, encabezando hoy la autodefensa y dando los pasos necesarios para asumir las tareas en una etapa superior de lucha". ${ }^{4}$

La reunión partidaria efectuada en diciembre de 1984, bautizada como el Pleno de 1985, también hizo mención al nacimiento de las MR, las que se habrían conformado en el paro nacional del 30 de octubre de 1984. Las MR eran vistas como un fenómeno nuevo, respondiendo más que todo "al ánimo de pelea de las masas y al prestigio que el FPMR ha adquirido en ellas". Respecto a la organización de las MR, se sostuvo que ellas no dependieron “del FPMR pero sí responden a una orientación de lucha paramilitar". Por lo tanto, una de las tareas propuestas era "promover su crecimiento, consolidar, pensar en su posible estructura, dirección y apertrechamiento, así como en el papel que se les asigne en la lucha de masas". Las responsables que las milicias progresaran eran las células comunistas, invitando a "luchadores independientes, sobre todo a los jóvenes en poblaciones, universidades, e industrias, a incorporarse a las milicias". 49

A partir de la información recopilada y los testimonios a los cuales tuvimos acceso, sostenemos que las MR fueron el intento del partido por consolidar el trabajo paramilitar de

\footnotetext{
47 "Extremistas se adjudicaron ola de atentados", El Mercurio, 19-10-1984, C-7.

48 "Primer manifiesto rodriguista", en Frente Patriótico Manuel Rodríguez, Manuel cabalga de nuevo, Santiago, Ediciones III aniversario, 1986, 163.

49 "Informe al Pleno del Comité Central del Partido Comunista de Chile, 1985. Para voltear a Pinochet el único camino es el enfrentamiento continuo y ascendente”, Hacia el congreso nacional, s/e, s/a, 111.
} 
masas en la segunda mitad de los años ochenta. No obstante, el afianzamiento de las MR, al igual que los CAM, estaban focalizadas en las poblaciones donde el partido tuvo una raíz histórica, especialmente en el sur de Santiago. Las MR realizaron acciones de sabotajes y propaganda en recintos educacionales, pero tuvo mayor organización en la periferia capitalina, donde vivían los pobladores y el partido actuaba abiertamente en las organizaciones sociales. Pese a que las fuentes consultadas señalan la presencia miliciana a lo largo de Chile, éstas no dieron una referencia específica, aunque es posible que en las urbes de las capitales regionales se hayan formado. Ramón Vargas entre 1983 y 1988 por actividades partidarias tuvo que transitar entre Antofagasta, Santiago y Valparaíso: desde 1983 hasta el primer semestre de 1985 fue el Secretario Regional de Antofagasta, retornando a la capital por un corto período, para luego ser Secretario Regional de Valparaíso entre 1986 y 1988. Su experiencia en tres regiones distintas lo lleva sentenciar que "en provincias las milicias se formaron sobretodo en Valparaíso, pero no tuvieron el mismo desarrollo que en Santiago". Mientras que en el norte, ante las urgencias de consolidar cuadros militares, sucedía "que se formaba un grupo y había que pasárselo al Frente". 50

Las MR lograron establecer una organización permanente con sus respectivos jefes y unidades milicianas, los cuales provenían del TMM y de las JJCC. Los encargados de las MR se contactaron permanentemente con miembros del FPMR previo a una jornada de movilización social, en el desarrollo de ésta y en su culminación. A pesar de los innumerables llamados a formar milicias, se debían cumplir requisitos mínimos para integrarse a ella:

La construcción de las milicias pasa por un trabajo de masas del PC, porque las milicias eran del PC, estaban conectadas con la política del PC. Entones, en las poblaciones regularmente se hacían marchas, marchas violentas, marchas reventones, y en esas marchas se reclutaba gente. Uno visualizaba las marchas y sabía que gente iba más armada y algunos cabros querían foguearse en las marchas, y los que eran buenos y decididos se conversaba con ellos, se les reclutaba incluso en la misma marcha. Pero eso lo definía la gente del territorio: "sí, este cabro nos da confianza, es bueno para la pelea, lo podemos integrar". No se integraba necesariamente a la jota sino a una estructura paralela, la milicia. Se le decía: "mira, ¿tú estás disponible para que te contactemos y te organicemos?”. Normalmente los cabros nos decían que sí. A los cabros se les hacía un chequeo, seguimiento, había todo un proceso para integrar gente a las milicias. ${ }^{51}$

Para comprender el fenómeno miliciano al interior del PCCh hay que retrotraerse al plan político-militar de la Sublevación Nacional (SN). Esta idea surgió de la lectura del Pleno de 1985, destacando que la fuerza militar propia y la actividad paramilitar de las masas adquirían mayor incidencia en la lucha sociopolítica. ${ }^{52}$ En los años de la sublevación el FPMR fortaleció sus fuerzas urbanas, que se dividían en las especiales y operativas: las primeras cumplían tareas de alto nivel militar (ataques a cuarteles policiales, militares y de la CNI, voladura de torres de alta tensión, ajusticiamientos, etc.), por lo que las

\footnotetext{
${ }^{50}$ Entrevista con Ramón Vargas, 15-07-2014.

${ }^{51}$ Entrevista con Marcelo 27-11-2014.

52 "Informe al Pleno del Comité Central del Partido Comunista de Chile, 1985", op. cit., 118-120.
} 
conformaban miembros con un alto grado profesional; las fuerzas operativas, mientras tanto, se orientaron al trabajo territorial en las principales poblaciones del país. A su vez, el TMM dio un salto cualitativo y las MR lograron consolidarse en los años que se desplegó esta política. ${ }^{53}$ Ahora bien, ¿qué era la SN y cuál era el rol que debían cumplir las masas en el terreno paramilitar?

El proyecto de la SN era comprendido como la etapa superior de la PRPM, donde se debería llegar a un estado permanente de ingobernabilidad hasta la derrota del régimen. Para lograrla, se conjugaba el factor político y las acciones armadas: el partido ordenaba esfuerzos superiores en torno a su política de alianzas con el fin de sumar más actores sociales y reivindicar sus causas; por otra parte, el elemento militar contribuiría a completar el ejercicio de la violencia revolucionaria de las masas. Ahora bien, se sugirió que llegado el momento culminante de la sublevación el aspecto militar alcanzaría una connotación cada vez más creciente, "revistiendo un carácter decisivo en la fase más alta de la SN y comprende el conjunto de acciones de masas y de fuerzas especializadas tendientes a desgastar al enemigo, desconcentrarlo, desarticularlo, empantanar sus fuerzas impidiendo su movilidad y apuntar a consolidar y defender lo ya avanzado". 54

La SN estaba dividida en cinco puntos: movilización activa y ascendente; paralización del país; golpes a las fuerzas represivas y militares; trabajo hacia las FF.AA. y de Orden; y el trabajo internacional. El primer ítem se orientaba a que las fuerzas políticas en conjunto convocaran jornadas de protesta en las principales ciudades del país: Valparaíso, Santiago y Concepción. La idea era que los participantes se distribuyesen en distintos puntos para dispersar a las fuerzas represivas, consumaran actos de agitación y se reagruparan si es que eran disueltos por el actuar policial. El objetivo de todo esto era provocar "levantamientos populares", para lo cual era necesario "fortalecer y consolidar unidades paramilitares (MR) destinándoles misiones específicas", como "masificar el empleo de barricadas en las vías y zonas principales, hacerlo en forma escalonada y con amplia utilización de fuego". Al mismo tiempo se debían "organizar emboscadas, en los pasos obligados del enemigo" y establecer contacto con "otras zonas liberadas del enemigo". Por último, las masas coparían "los principales centros políticos y públicos de la zona".

En cuanto a la paralización total del país, ésta se enfocaba en detener el proceso productivo de la minería, la industria, las faenas agropecuarias, el sistema eléctrico, de comunicación y transportes. Había que impulsar paros en sectores claves de la economía hasta lograr la huelga general, objetivo último de la SN. La actividad militar cumpliría un rol imprescindible en obstaculizar la producción, mediante sabotajes explosivos en ramas estratégicas, voladura de puentes, control de carreteras, complejos industriales y agrícolas.

En el tercer punto, la fuerza propia del partido tendría mayor incidencia en perpetrar golpes selectivos a la represión y las FF.AA. "más incondicionales del fascismo", ajusticiando a los "jefes militares y políticos más comprometidos". Se promovía también golpes a las unidades móviles destinadas a la represión y ataques a las "industrias que juegan un papel de aseguramiento y apoyo logístico a las fuerzas militares”. El éxito de las

\footnotetext{
${ }^{53}$ Frente Patriótico Manuel Rodríguez, "A fortalecer la base y los principios rodriguistas construyendo el instrumento patriótico para la revolución", Archivo Histórico Centro de Estudios Miguel Enríquez, CEME, Santiago, 2000, 17.

54 "Fundamentos del plan de la SN", sin fecha (1985?), 5. Subrayado en el original.
} 
acciones armadas estaba determinado por "la combinación de los golpes tanto en las ciudades como áreas periféricas".

En lo que concierne al trabajo hacia las FF.AA. y de Orden y el trabajo internacional, eran parte de la etapa previa de la SN. En el primer caso, sólo a través de propaganda y la "lucha sicológica" se invitaba a los uniformados a la "lucha antifascista". El segundo ítem apuntaba a lograr "los medios básicos de aseguramiento y ayuda financiera", a la cual se debían sumar declaraciones públicas de "solidaridad internacional". Era menester "crear la superestructura necesaria en el país vecino que garantice las siguientes tareas: reagrupamientos de los exiliados políticos y compatriotas que se encuentran en el exterior". 55

Este proyecto político-militar era una tarea titánica, debiendo conjugarse una serie de factores para acabar con el gobierno de facto. La SN nos muestra por lo que abogó el partido en estos años: la mixtura de la política y el desarrollo militar, siendo esta última en función de la primera. En ningún momento el documento citado expuso que la SN era un enfrentamiento contra Ejército chileno; más que todo se aventuraba por la derrota política del régimen, en que la acción decidida de las masas acompañada por sabotajes superiores neutralizaría e inhibiría a los sectores más acérrimos a la dictadura. Lo relevante era que las masas debían participar de la actividad huelguista, coparan el centro de las principales ciudades y se sumara al trabajo paramilitar, donde las MR cumplirían a cabalidad ese rol. La SN nos muestra un partido enfocado en la planificación de las acciones políticomilitares, estudiando las fuerzas enemigas, seleccionando cuadros y creando la infraestructura necesaria para garantizar la $\mathrm{SN}$.

Como la SN necesitaba mayor despliegue del rol paramilitar de masas, las MR llegaron a tener su propia revista, bautizada como Barricada. La primera editorial sostuvo ser el "órgano de las Milicias Rodriguistas", dotando "al pueblo de Chile de un instrumento de lucha". Junto con esto, destacó que "sólo la Sublevación Nacional, el levantamiento de todo el pueblo, nos traerá el fin de esta obscura noche y el ansiado retorno a la democracia”. Barricada se propuso varios objetivos: entregar elementos teóricos que permitiesen enfrentar con éxito a las fuerzas represivas; enseñar técnicas de primeros auxilios; adiestramiento de cómo protegerse del enemigo, "identificar a los sapos, y aniquilar a los sapos"; realizar trabajo conspirativo para no ser detectados por los órganos de seguridad; y mejorar el ocultamiento de armas ante los allanamientos sorpresivos que ejecutaban cada cierto tiempo los organismos de seguridad. ${ }^{56}$ Aunque el objetivo de la revista era que circulara de mano en mano, ésta era una tarea compleja de cumplir por los riesgos de mantener una publicación considerada subversiva. No fue raro, entonces, que la creatividad floreciera y que a los milicianos llegase información por otros medios. Marcelo nos señala que incluso se levantaron códigos escritos que fueron repartidos en la población como fue el Salmo nueve. Este salmo era una cartilla que en su cara frontal estaban los versículos bíblicos, mientras que en la parte posterior estaba la instrucción miliciana. Eran 29 cartillas con tácticas de autodefensa, tareas asignadas, análisis de las fuerzas opositoras, fabricación de armamento casero, entre otras. ${ }^{57}$

\footnotetext{
${ }^{55}$ Las citas en ibid, 5-7.

56 "Editorial", Barricada, No 1, Marzo de 1985, 2.

${ }^{57}$ Entrevista con Marcelo 27-11-2014.
} 
La actividad miliciana se dividía en "Grupos" y contemplaba seis puntos en su actuar: Grupos Diversionistas, Grupos de Exploración, Grupos de Contención, Grupos de Choque, Grupos de Seguridad y Grupos de Reserva. El primer grupo tenía como misión fundamental distraer a la represión mediante sabotajes menores o incendiarios, con explosivos caseros y esparcimiento de neumáticos en llamas en diferentes avenidas y a distintas horas. La idea era provocar al enemigo, pero dividiéndolo en su proceder. En segundo lugar, los grupos de exploración estaban compuestos por milicianos que actuaban solos, cumpliendo con la misión de observar el terreno elegido dónde se realizaría la actividad política y la posible reacción de las fuerzas represivas. Los exploradores eran los ojos del jefe y actuaban antes, durante y después de la operación miliciana. Su rol era colocarse en lugares altos para visualizar el movimiento de Carabineros y dar cuenta si éstos se acercaban o alejaban de la actividad de masas. Los Grupos de Contención, por su parte, debían impedir el acceso de la policía a la población o una actividad pública, la cual se lograba con el derribamiento de árboles, construcción de zanjas y barricadas, lanzamiento de miguelitos, atravesar autos, entre otros. De fallar la contención, los Grupos de Choque serían los responsables de romper el cerco enemigo y permitirían que las masas no fusen atacadas. Por lo general, los grupos de choque estaban compuestos por los milicianos más instruidos y con mayor armamento, pues de ellos dependía el éxito o fracaso de una actividad política de masas, neutralizando y atacando el actuar represivo. Los Grupos de Seguridad participaban del acto, repeliendo así los ataques imprevistos de la policía cuando lograba romper el cerco y a los grupos de choque. Eran los responsables de proteger a los dirigentes, pero su tarea principal era cubrir puestos si hubiese bajas en las distintas operaciones milicianas. ${ }^{58}$

El trabajo paramilitar contemplaba la autodefensa, la instrucción y la organización en la lucha callejera, con el objetivo de consolidar "territorios liberados" o "focos poblacionales". Un mando miliciano detallaba que los territorios liberados era cuando los pobladores a través de la autodefensa de masas lograban detener la represión y controlaban el sector. El miliciano enfatizaba que "el concepto de territorio liberado es no dejar entrar a la represión y, a su vez, empezar a cachar sapos y soplones y poder, en este caso, ayudar a democratizar las juntas de vecinos". Para lograr aquello, se crearon "mandos correspondientes para estructurar una buena organización, para operar en la defensa de los pasajes, calles y arterias principales, donde las masas populares eran orientados por las MR al cavar zanjas construir barricadas, etc." 59 Bajo esta idea no fue raro que la militancia comunista hablara de zonas liberadas:

Compañeros: Pudahuel es una comuna y en ella tenemos poblaciones que anteriormente eran poblaciones Focos; ahora producto de una acertada política

\footnotetext{
58 “Misiones de los milicianos y combatientes en una operación de autodefensa de masas", El Rodriguista, № 25, junio de 1987, 37-40. Como se sabe, El Rodriguista era la publicación oficial del FPMR, el cual luego del quiebre siguió editándose tanto por los autónomos que se fueron con Raúl Pellegrin y por los rodriguistas que permanecieron fieles al PCCh. Aun así, el nombre de la publicación no varió un ápice, pero la única diferencia es que El Rodriguista publicado por los autónomos en el índice de la revista colocaba las siglas GPN (Guerra Patriótica Nacional), proyecto político-militar con el cual actuaron los rodriguistas en su vida independiente. Esto lo señalamos porque en este trabajo hemos usado El Rodriguistas, los cuales fueron editados por el FPMR que permaneció en el PCCh después del quiebre.

59 "Impresionante autodefensa de masas", El Siglo, No 7634, primera quincena de agosto de 1986, 9.
} 
del Partido y las masas, son Zonas Liberadas, dentro del concepto de sublevación nacional, desde el mes de septiembre pasado. Herminda de la Victoria, Liberación, Violeta Parra, Sara Gajardo, Montijo, Yugoeslavia, Neptuno, La Estrella, San Daniel, Teniente Merino, San Francisco, todas ellas de Pudahuel. Simón Bolívar, Cañada Norte, Manuel Rodríguez, Zelda, Las Mercedes, Sta. Anita, La Paula, Las Palmeras de Quinta Normal. ${ }^{60}$

Carlos durante los años ochenta tuvo contacto directo con las MR que estaban esparcidas en distintos puntos de la capital, pero siendo más notorias en el sur de Santiago. Su testimonio acentúa que la liberación de territorios no era tan amplia como solía indicarse:

No hacían grandes liberaciones de poblaciones. Cada milicia tenía encargado un pequeño sector y las milicias a veces se organizaban por pasajes de la población. Entonces la orden de la milicia era mantener liberado el espacio durante la jornada de movilización, que no entrara la repre. Y si entraba seguir combatiendo. O sea, llegaba un momento determinado en que, por ejemplo, los blindados lograban romper el cerco de las barricadas, pero nosotros nos íbamos y nos subíamos a los techos y desde los techos tirábamos molotov, disparábamos, los dejábamos pasar, y después se volvía a recuperar la calle. No era dejarlos tranquilos porque si la repre se instalaba en la población te podían allanar, te podían detener. Entonces lo que hacia la repre era disparar más que quedarse en un lugar. La misión de los pacos y de los milicos era tratar un día antes quedarse en los puntos neurálgicos y tomárselos. Por ejemplo, avenida la Feria con Departamental siempre llegaban los milicos un día antes, pero la gente desde dentro les disparaba y los movía y así no tenían punto de referencia. Entonces la función de las milicias era mover esa represión y golpear en movimiento, que es una técnica de combate guerrillero, y en lo posible recuperar armamento y si era posible ajusticiar chanchos dentro de la población. ${ }^{61}$

Un dirigente comunista de Santiago refiriéndose a las MR expresó que el pueblo se incorporaba de forma voluntaria a ellas, solicitando las escarapelas distintivas y sintiéndose milicianos. Fue enfático al exponer que las MR surgieron al calor del "combate callejero, y a ellas se integran militantes del partido y gente sin partido, los más audaces, peleadores, valientes, los más luchadores". Sin embargo, había jefes y se organizaban en "grupos de 1 por 5, 1 por 10 o 1 por 50”. Las palabras del dirigente daban cuenta que las milicias crecían insospechadamente en los días de protestas, sumándose a las tareas entre doscientas o trescientos individuos. Lo relevante era que la milicia gozaba de una "organización de manera estable por la dirección y la organización de la vanguardia", donde los "comunistas

\footnotetext{
60 "Vida del Partido", El Siglo, N ${ }^{\mathrm{o}} 7620$, segunda quincena de diciembre de 1985, 2.

${ }^{61}$ Entrevista con Carlos 15-08-2014. Antiguo militante comunista que ingresó a las JJCC el año 1982, cuando cursaba tercero medio. En una época vertiginosa participó en las protestas nacionales, marchas del hambre y las jornadas de movilización poblacional, adquiriendo experiencia combativa contra las Fuerzas Especiales de Carabineros. El partido estaba urgido por incorporar cuadros militares, por lo que en 1985 fue invitado a pasar al FPMR. Luego del quiebre con el partido se incorporó de lleno al proyecto de los autónomos. A petición del entrevistado usaremos el seudónimo por el cual era conocido.
} 
nos incorporamos a ellas y fomentamos su organización, su mayor conciencia y su preparación". ${ }^{2}$ En cuanto a esto último, también era importante realizar un trabajo ideológico, advirtiendo a los milicianos que los hechos de violencia política era con un objetivo concreto: derrotar a la dictadura. Marcelo al respecto indica que se intentó hacer un trabajo político a los jóvenes que ingresaban a las milicias para evitar que actuaran con fines propios, alejándose del criterio de masas del partido: "Se trató de adoctrinar, porque tú cuando manejas armas te acostumbras. Ya tienes la capacidad operativa de hacer asaltos y otras cosas más. Por eso la formación del miliciano también hubo un discurso político". 63

Aunque se llamaba a la más amplia ciudadanía para formar MR, el rango etario y de clase que las componían eran primordialmente jóvenes de extracción popular que habían tenido vínculos con las JJCC en sus espacios de socialización. Ejemplo de ello es el caso de un joven miliciano de 16 años, conocido como "el pelao", que vivía en el área sur de Santiago:

Yo me dí cuenta rápidamente como a los 12 años en el 83 que a nosotros los pobres la dictadura nos trataba como a enemigos y que la única manera de terminar con el hambre y la pobreza era que se fuera Pinochet. Me ayudó mucho a darme cuenta de estas cosas conversar con los cabros de la Jota en la escuela y aquí en la población. Así que en el 84 entré a la Jota aquí en el barrio". 64

El relato demostraba cómo las experiencias de vida y la actividad política lo llevaron a engrosar las filas milicianas. En junio de 1986 un compañero le señaló la necesidad de efectuar trabajo de autodefensa de masas, por lo que ingresó a las "Milicias Rodriguistas un poco antes del Paro Nacional. Tenía 14 años cuando empecé”. Su unidad estaba compuesta "casi por puros jóvenes, pero en otras hay de todas las edades, eso no tiene importancia. También participan hombres y mujeres y hasta niños a veces cumplen misiones, todo depende del momento y de la tarea". ${ }^{65}$ Nelson Rivera fue parte del Comité Local de las JJCC de la población Yungay, para luego convertirse en el encargado de las MR de su sector. Su testimonio complementa lo expuesto hasta ahora: las milicias las componían jóvenes pobladores con o sin militancia comunista: "Aunque no se crea organizamos Milicias Rodriguistas y fuimos reconocidos por la dirección del partido, sin ser estos jóvenes militantes de partidos políticos, sino queriendo defender la población. Eran unas 45 personas, que no querían ser de ningún partido político". 66 Marcelo al respecto sentencia: "Las milicias eran cabros, los que iban al choque eran cabros. Teníamos gente de 15 años peleando en las milicias. De repente no se podían el fierro o se morían de susto". 67

Además de la defensa de la población, las MR constantemente efectuaban agitación y propaganda política que en algunos casos podía ser armada. En enero de 1986 en La Victoria se celebraron los 64 años del PCCh, realizándose actividades culturales y

62 "El trabajo del Partido en Santiago", Boletín del Exterior, № 76, enero-febrero de 1986, 19-20.

${ }^{63}$ Entrevista con Marcelo 27-11-2014.

64“"Yo soy un miliciano rodriguista", El Rodriguista, No 34, octubre de 1988, 10.

${ }^{65}$ Ibid., 11-12.

${ }^{66}$ Nelson Rivera, en Herreros, op. cit., 524.

${ }^{67}$ Entrevista con Marcelo 27-11-2014. 
pronunciando un discurso la presidenta del Comando de Pobladores de La Victoria, Claudina Núñez. Cuando terminaban las palabras de la dirigente irrumpieron con un desfile las MR, saludando el cumpleaños de la organización. En la calle 30 de octubre con Galo González "30 milicianos marchando, vestidos todos de camisa blanca, boina negra, bluyín azul y pañuelo rojo y celeste con las letras "MR" al cuello, conducidos por una muchacha comandante". ${ }^{68}$ La idea de las marchas en el corazón de la población era dar cuenta de la liberación de los territorios, evidenciando que la represión podría ser derrotada: "Organizado por la Milicia Rodriguista, el jueves 3 en la tarde, en la población Yungay, y cuando otros sectores sometidos a operaciones de virtual guerra, por efectivos del Ejército y Carabineros, se celebró con una marcha su territorio liberado". 69 Como hacer propaganda armada era riesgoso para los participantes, la agitación miliciana tuvo códigos por si eran detenidos:

Uno iba chapeado, o sea, a mi cuando me mandaron a hacer la primera actividad de agitación y propaganda llegó un viejo y me dijo: "Te voy a pasar 500 pesos. Si te agarran di que te pagaron por esto y el resto te van a pagar cuando termines". Entonces se le quitaba un componente político que podía ser complejo porque podían enjuiciarte como terrorista. En cambio con lo otro pasabas a ser un delincuente común. ${ }^{70}$

Los milicianos destacaron que hubo una evolución natural en la lucha callejera, expresada en mejor armamento, tácticas de autodefensa superiores y empleo de barricadas mayores. Un miliciano del sur de Santiago relató que a inicios de la década la autodefensa de masas consistía en tirar piedras, prender fogatas y desparramar basura como obstáculo, pero luego se avanzó a "la construcción de barricadas de contención, aprendimos a fabricar explosivos y con ayuda de trabajadores torneros fuimos creando nuevos tipos de granada, tuvimos que hacernos prácticos en la lucha, cuerpo a cuerpo y en tácticas militares". ${ }^{71}$ Un miliciano de La Legua relató: "En el 80 lo que se empezó a hacer fue quemar neumáticos, luego se empezó a enseñar cómo preparar una barricada, cómo convertir cada elemento casero en herramienta para contener a los pacos, surgieron las hondas, los hostigamientos a pedradas". Aunque se intentaba proyectar una racionalización en cuanto a la autodefensa de masas, el miliciano reconocía que la espontaneidad continuaba predominando en las jornadas de protestas, pues los participantes "abren los grifos de las veredas, se arrojan colchones, elásticos de cama, sillones y cualquier cosa para fortalecer las barricadas: es un cuadro surrealista donde los pobladores, a través de la acción, se liberan espiritualmente y van a la pelea. Los más combativos son los que se van incorporando a las milicias". ${ }^{2}$

A diferencia de los CAM, las MR se caracterizaron por el uso de armamentos artesanales y el dominio de elementos explosivos. Cabe anotar que esta actividad no fue monopolio de las MR, ya que dentro de la compleja estructura militar del PCCh las

\footnotetext{
68 “El 64 aniversario en La Victoria”, El Siglo, № 7621, primera quincena de enero de 1986, 8.

69 “Frente Patriótico Manuel Rodríguez", El Siglo, Extra, 4 de julio de 1986, 7.

${ }^{70}$ Entrevista con Marcelo 27-11-2014.

${ }^{71}$ El testimonio del miliciano rodriguista en Arturo Lozza, op. cit., 9-10.

${ }^{72}$ Testimonio tomado de Ramón Cataldi, Chile, la rebelión popular. Reportaje al FPMR y la resistencia (Enviado especial de Qué pasa), Buenos Aires, Editorial Ateneo, 1986, 25.
} 
Unidades de Combate también las manejaban. ${ }^{73}$ El encargado de las milicias por lo general era propietario de un arma corta, pero la mayoría de los milicianos manipulaban bombas de ruido, de humo, pólvora negra, lanzaba granadas de fabricación artesanal contra la represión como el niple y la molotov química. Para cortar la luz de forma local se colocaban bombas de potencia menor en los postes, pero que permitía el derribamiento de éstos: "Una vez llegaron a las milicias las manzanitas, un explosivo circular, como una manzana, la cual al centro iba con una perforación, un estopín y una mecha. Se ponía en los hoyitos de los postes y éste se caía, cortando la luz. Era mucho más bacán que tirar las cadenas a los cables". ${ }^{74} \mathrm{El}$ armamento dependía mucho de qué grado de organización habrían logrado las MR: "Hemos construido armamento casero: flechas, lanzas, bombas de mano, hondas y por allí me llegaron unas pitufas que son escopetas hechizas súper buenas. En todo caso lo que más usamos son las piedras y los explosivos caseros. Ah, se me olvidaba la molotov que es básica en la pelea". ${ }^{75}$ Sin embargo, predominó el uso de armas de fuego artesanal, como los "matagatos, una que otra pistola más grande. Nos enfrentábamos, no tanto a tiros, sino más bien con granadas caseras, con ellas lográbamos hacer retroceder a las fuerzas policiales" ${ }^{76}$

Por lo visto hasta ahora, se desprende que las MR fueron una organización más que todo poblacional, compuesta sustancialmente por jóvenes con un discurso político mezclado con individuos que se sumaron a ella para resistir la arremetida dictatorial en los días de protesta. Tanto los testimonios como los documentos nos indican que éstas se desarrollaron puntualmente en el sector sur de Santiago (La Victoria, La Legua, Legua Emergencia, El Pinar, La Bandera, José María Caro, Joao Goulart, Yungay), aunque también hubo milicias en el norte de la capital (La Pincoya, El Cortijo y Juanita Aguirre), por el oriente (Lo Hermida, Jaime Eyzaguirre y población Santa Julia) y en el poniente se concentró la actividad sustancialmente en Pudahuel. Al ser una organización que oscilaba por pasajes y avenidas, donde el espacio de socialización se reduce a unos cuantos lugares (iglesia, canchas de futbol, colegios, ferias libres, junta de vecinos), el conflicto más habitual y con el que más tuvo que enfrentarse las MR era con los delatores, o sapos en el lenguaje cotidiano. Obviamente no todos los pobladores eran contrarios al régimen militar e incluso la Unión Demócrata Independiente, UDI, forjó una importante base de apoyo en algunas poblaciones. Los que estaban a favor del régimen eran los sapos, los cuales fueron víctimas de la agresión miliciana en más de una ocasión en el marco de una jornada opositora: "La milicia tenía lista de posibles sapos y en las jornadas de protesta se verificaban si eran sapos o no. Así varios sapos quedaron fuera de combate por parte de las milicias más que del mismo Frente". ${ }^{77}$ Una de las tareas milicianas era "reventar a los sapos. Muchas veces la milicia reventó chanchos, sapos. Se le ponía su carga en la ventana o se mandaba un informe y venia una unidad especializada y demolía parte de la casa. Se ponía una carga fuerte". ${ }^{78}$

\footnotetext{
${ }^{73}$ Sobre las Unidades de Combate, Álvarez, Arriba los pobres...op. cit., 229.

${ }^{74}$ Entrevista con Marcelo 27-11-2014.

75 "Yo soy un miliciano rodriguista", op. cit., 12.

${ }^{76}$ Nelson Rivera, en Herreros, op. cit., 525.

${ }^{77}$ Entrevista con Carlos 15-08-2014.

${ }^{78}$ Entrevista con Marcelo 27-11-2014.
} 
Era práctica común que en la lucha contra la dictadura se mezclara actividad de las milicias con las fuerzas operativas del FPMR. En La Victoria, por ejemplo, funcionaron 10 unidades milicianas y dos unidades operativas del FPMR: la primera la conformaban 10 a 15 personas de forma estable, mientras que la segunda la compusieron 5 combatientes rodriguistas. $^{79}$

Para las jornadas de protesta la milicia organizaba más que el PC, que no se veía, o sea, todos sabíamos que los comunistas estaban metidos, pero la milicia era la que llevaba la voz cantante en el trabajo militar de la población, del territorio. Entonces cuando la milicia estaba organizada y combatiendo normalmente aparecían unidades del Frente, que eran mucho menos, más chiquititas. Una milicia podía tener quince personas trabajando en esa unidad miliciana y se juntaban cuatro o cinco milicias para contener una población y en un momento llegaban cuatro o cinco compañeros del Frente, no más de eso. ${ }^{80}$

Las acciones conjuntas más las necesidades del partido de aumentar los cuadros hacia la fuerza militar propia en los días de la SN, significó que un número importante de milicianos engrosaron las filas del FPMR. Este fenómeno se consolidó mediante un doble proceso: "Había mucha insistencia de la Dirección sobre los regionales o los comités locales para pasar gente al Frente, aunque habían compañeros que participaban en las milicias y en un momento determinado como que les daba la vocación integrarse de una manera más militar". ${ }^{81}$ Por más que la vocación estuviese presente en los milicianos no todos ingresaron al FPMR; se sumaron a la fuerza militar del PCCh los jóvenes que más se foguearon en las barricadas, los más audaces, con experiencia y mejor dinámica en la lucha antidicatorial, aunque la gran mayoría eran recomendados por los jefes milicianos. Carlos es categórico al recordar que el criterio de selección de combatientes rodriguistas era riguroso: "Los mejores cuadros de la milicia pasaban al frente, en un filtro que se hacía ahí, se le estudiaba al compañero, se veía si tenía disciplina, si no era borracho, si no era drogadicto, si no tenía malas mañas y una serie de elementos más, y los mejores cuadros empezaron a nutrir al Frente Patriótico Manuel Rodríguez". ${ }^{2}$

Como las MR se explican por la SN que emprendió el partido finalizando 1984, éstas decantaron notoriamente cuando la política insurreccional llegó a su fin y una parte importante de cuadros militares se autonomizaron marchándose con Raúl Pellegrini a mediados de 1987. Aquel año fue particularmente crítico con la desarticulación del movimiento social a causa del Estado de sitio impuesto por la dictadura luego del fallido ajusticiamiento a Pinochet el 7 de septiembre de 1986 y por escuálidas convocatorias a jornadas de movilización. A pesar que tanto los CAM y las MR siguieron operando, desde 1987 se dieron dos fenómenos que no fueron disímiles al quiebre entre el PCCh y una parte del FPMR. Los testimonios provenientes de comunistas argumentaron que las milicias fueron diluyéndose a causa de las escasas movilizaciones sociales de aquel año. El testimonio de Nelson Rivera da cuenta cómo el partido había dejado atrás la autodefensa de

\footnotetext{
${ }^{79}$ Idem.

${ }^{80}$ Entrevista con Carlos 15-08- 2014.

${ }^{81}$ Entrevista con Ramón Vargas 15-07-2014.

${ }^{82}$ Entrevista con Carlos 15-08- 2014.
} 
masas para concretarse exclusivamente en cuestiones políticas, lo que no fue un proceso simple y ajeno de contradicciones:

El 87 me fui preso otra vez, por participar en un paro. Los pacos de San Gregorio me sorprendieron con un revólver y explosivos caseros. Estuve preso en la penitenciaria creo que hasta 1989. Cuando salgo, el panorama político había cambiado. El PC estaba trabajando para legalizarse. Legalizarse ante la dictadura era una contradicción que no entendíamos. Por instinto y conciencia, no se puede concebir. Se cambió la autodefensa por brochas y pintura. Anduve perdido no sé cuánto tiempo. Igual organizábamos BRP (Brigadas Ramona Parra) con la gente que estaba antes. Seguimos trabajando en los primero de mayo y algunas actividades grandes y manifestaciones, organizando a la gente. No lo entendía, después de tantos años de formación contra la dictadura, tratando de simpatizar quizá, tratando de hacer legal algo donde nada podía ser legal. Era algo que no quería aceptar, pero que como militante disciplinado tenía que aceptar, sin quererlo, como mucha gente lo ha hecho. ${ }^{83}$

El quiebre entre el PCCh y el FPMR significó que este último tuviese que realizar esfuerzos superiores para reclutar cuadros y poder perpetrar las operaciones enfocadas ahora en el marco de la Guerra Patriótica Nacional (GPN). ${ }^{84}$ Los rodriguistas que se sumaron al proyecto de Raúl Pellegrini señalaron, sin vacilación, que las milicias crecieron en cuanto a número, pero éstas adquirieron nuevas tareas. Es decir, la prevalencia de la concepción militar hizo que las MR transitaran de una organización paramilitar que actuaba con las masas a grupos operativos, alejados de ellas.

Se perdió el objetivo de la milicia que era la territorialidad, todos querían ser estrellas. La figura, la competencia entre zonas se llevó al extremo. Las milicias quedaron huérfanas, acéfalas, porque las milicias dejaron de hacer trabajo de milicias y se disolvieron, tácitamente se disolvieron, porque pasaron a ser del Frente. Por lo tanto ¿Quién hacía el trabajo territorial? Nadie. Por eso te digo, se pierde el objetivo, se cortó el vínculo con el pueblo. Se militarizó en el mal sentido de la palabra con la GPN. ${ }^{85}$

Las milicias crecen después del quiebre, crecen mucho, pero con variaciones. Las milicias crecen masivamente porque el Frente necesitaba a la milicia. Raúl (Pellegrini) habló del rediseño, que tiene que ver que ya no contamos con el apoyo del PC, sí en las bases pero no en la cúpula. Por lo tanto, las milicias crecen, pero ya no hay apoyo del PC, no habiendo filtro de quién entraba a la milicia. Y eso degeneró a la milicia, se quedó peleando sola y se quedó frente a los graves problemas del F (Frente). Por ejemplo, el año 89 seguía habiendo milicias, pero ya se pierden ciertos objetivos políticos. La milicia tiene que reinventarse, pero ese reinventarse significó radicalizarse. Si inicialmente a la milicia se le pasaba una (calibre) 22, su matagato y todo, pero después del quiebre estaba la necesidad de realizar operaciones de mayor envergadura por parte de las milicias. Se pasó la raya. La milicia atacaba cuarteles, desarmaba

\footnotetext{
${ }^{83}$ Nelson Rivera en Herreros, op. cit. pp. 548-549.

${ }^{84}$ Sobre este proyecto político militar impulsado por Raúl Pellegrini, Rojas, op. cit. 403-463.

${ }^{85}$ Entrevista con Carlos 15-08-2014.
} 
pacos y militares que estuvieran en la calle, le quitaban los fierros, a los guardias se les quitaba la munición. Muchas veces se hicieron asaltos con pistolas sin balas. Se mezcló mucho, se empezó a diluir la línea entre la milicia y el frente. ${ }^{86}$

\section{Palabras finales}

A lo largo de esta investigación hemos intentado demostrar un hecho puntual: la autodefensa de masas fue una parte fundamental de la política militar del PCCh, la cual se hizo más notoria en las jornadas de protesta. A pesar de las dificultades iniciales, y discrepancias ante los nuevos rumbos que tomaba el partido para enfrentar al régimen, se logró consolidar una estructura militar partidaria que se fusionó con el trabajo a nivel de bases en las poblaciones de Santiago.

La simbiosis entre la política y la violencia del período se explicaría por la experiencia adquirida, tanto por los militantes comunistas como los sectores populares en sus espacios de socialización: los primeros, optaban por ingresar al brazo armado o realizar actividad política clandestina; los segundos, mientras tanto, desde la cotidianeidad y la práctica de resistir la arremetida policial, junto a una radicalización política que se vivió en segmentos juveniles y poblacionales, derivó que algunos decidieran realizar actividad miliciana y perfeccionar la resistencia civil contra los aparatos armados. Es decir, la teoría y la praxis política antidictatorial provocaron cuadros militares con una alta capacidad de ejercer violencia contra las instituciones armadas, mientras que las milicias permitieron liberar por algunos instantes a las poblaciones de la represión, ejercer actividad política y perseguir a los delatores.

La actividad paramilitar por la cual el partido colocó todos sus esfuerzos en estos años, desde nuestra óptica, permitió concretar la PRPM, puesto que en los CAM y en las MR era viable realizar actividad partidaria y ejercer todas las formas de lucha, donde la violencia política apuntaba a un proyecto puntual: la caída de la dictadura y su orden social. Las MR, a su vez, nos muestran cómo el PCCh apostó por su política insurreccional, en que el desarrollo paramilitar era una necesidad sustancial para lograr la SN. Estas milicias fueron importantes a la hora de aportar cuadros al FPMR en los años en que se desplegó esta alternativa de enfrentamiento sociopolítico, pero significó que la experiencia miliciana fuese abrupta y fugaz por las urgencias de aumentar el número de combatientes rodriguistas. Luego del quiebre con el FPMR a mediados de 1987 fueron diluyéndose por parte del partido por las nuevas directrices en torno a la lucha contra la dictadura, mientras que los autónomos se esforzaron por lograr que las milicias consumaran actividades de envergadura superior, aunque esto derivó en su alejamiento de las masas y diluyéndose el proyecto original.

\footnotetext{
${ }^{86}$ Entrevista con Marcelo 27-11-2014.
} 


\section{Bibliografía y fuentes}

Libros y artículos

Álvarez, Rolando, Desde las sombras, una historia de la clandestinidad comunista (1973-1980), Santiago, LOM Ediciones, 2003.

Álvarez, Rolando, "El movimiento estudiantil secundario bajo dictaduras y las juventudes comunistas: un caso de radicalización política de masas", Alternativa, 23, Santiago, 2005.

Álvarez, Rolando, “Los hermanos Rodriguistas. La división del Frente Patriótico Manuel Rodríguez y el nacimiento de una nueva cultura política en la izquierda chilena. 1975-1987, Revista Izquierdas, 3:2, Santiago, 2009.

Álvarez, Rolando, Arriba los pobres del mundo. Cultura e identidad política del Partido Comunista de Chile entre democracia y dictadura. 1965-1990, Santiago, LOM Ediciones, 2011.

Álvarez, Rolando, "El Frente Patriótico Manuel Rodríguez: génesis y desarrollo de la experiencia de la lucha armada del Partido Comunista contra la dictadura de Pinochet", Taller (segunda época), 2:2, Buenos Aires, 2013.

Aróstegui, Julio, "Violencia, sociedad y política: la definición de la violencia", Ayer, 13:1, Madrid, 1994.

Aróstegui, Julio, "La violencia política y su dimensión histórica", Antonio Rivera y Carlos Carncero (Eds.), Violencia política. Historia, memorias, víctimas, Madrid, Maia Ediciones, 2010.

Braud, Philippe, Violencias políticas, Madrid, Alianza Editorial, 2006.

Bravo, Viviana, Con la razón y la fuerza venceremos. La Rebelión Popular y la subjetividad comunista en los '80, Santiago, Ariadna Ediciones, 2010.

Cataldi, Ramón, Chile, la rebelión popular. Reportaje al FPMR y la resistencia (Enviado especial de Qué pasa), Buenos Aires, Editorial Ateneo, 1986.

De la Maza, Gonzalo, Garcés, Mario, La explosión de las mayorías. Protesta nacional, 1983-1984, Santiago, ECO, 1985.

Frente Patriótico Manuel Rodríguez, Manuel cabalga de nuevo, Santiago, Ediciones III aniversario, 1986.

Goicovic, Igor, “Transición y violencia política en Chile (1988-1994), Ayer, 79:3, Madrid, 2010.

Goicovic, Igor, "Temas y debates en la historia de la violencia política en Chile", Contenciosa, 3, Santa Fe, 2014.

Grüner, Eduardo, Las formas de la espada. Miseria de la teoría política de la violencia, Buenos Aires, Ediciones Coligue, 2007. 
Herreros, Francisco, Del gobierno del pueblo a la rebelión popular, Santiago, Ediciones Siglo XXI, 2003.

Juliá, Santos, (Ed.), Violencia Política en la España del siglo XX, Madrid, Taurus, 2000.

Quiroz, César, "La política de rebelión popular de masas", Manuel Loyola y Jorge Rojas, Por un rojo amanecer. Hacia una historia de los comunistas chilenos, Santiago, Impresora Valus, 2000.

Lozza, Arturo, Chile sublevado. Reportaje al FPMR, Buenos Aires, Editorial ANTARCA, 1986.

Martínez, Luis, "Lo Militar y el FPMR en la política de Rebelión Popular de Masas: orígenes y desarrollo, Alternativa, 23, Santiago, 2005.

Moulián, Tomás, Chile Actual. Anatomía de un mito, Santiago, ARCIS-LOM Ediciones, 1997.

Moulian, Tomás, Torres, Isabel, "Continuidad o cambio en la línea política del Partido Comunista de Chile", Augusto Varas, (Comp.), El Partido Comunista en Chile: estudio multidisciplinario, Santiago, FLACSO-CESOC, 1988.

Pérez, Claudio, "Violencia y política en las publicaciones clandestinas bajo Pinochet: la palabra armada en el Frente Patriótico Manuel Rodríguez. Chile, 1983-1987”, Revista Historia Social y de las Mentalidades, 12:2, Santiago, 2008.

Pérez, Claudio, "De la guerra contra Somoza a la guerra contra Pinochet. La experiencia internacionalista revolucionaria en Nicaragua y la construcción de la fuerza militar propia del Partido Comunista de Chile", Pablo Pozzi y Claudio Pérez (Eds.), Historia oral e historia política: izquierda y lucha armada en América Latina, 1960-1990, Santiago, LOM Ediciones, 2012.

Pozzi, Pablo, Pérez, Claudio (Eds.), Historia oral e historia política: izquierda y lucha armada en América Latina, 1960-1990, Santiago, LOM Ediciones, 2012.

Rettig, Raúl, (Coord.), Informe de la Comisión Nacional de Verdad y Reconciliación, Santiago, Andros Impresores, 1996.

Riquelme, Alfredo, Rojo atardecer. El comunismo chileno entre dictadura y democracia, Santiago, Centro de Investigaciones Diego Barros Arana, 2009.

Rojas, Luis, De la rebelión popular a la sublevación imaginada. Antecedentes de la historia política y militar del Partido Comunista de Chile y del FPMR, 1973-1990, Santiago, LOM Ediciones, 2011.

Rosas, Pedro, Rebeldía, subversión y prisión política: crimen y castigo en la transición chilena, 1990-2004, Santiago, LOM Ediciones, 2004.

Salazar, Gabriel, Violencia política popular en las "Grandes Alamedas". Santiago de Chile 19471987. (Una perspectiva histórico- popular), Santiago, LOM Ediciones, 2006.

Samaniego, Augusto, "Lo militar en la política: lectura sobre el cambio estratégico en el PC. Chile, 1973-1983”, Revista de Historia y Ciencias Sociales Palimpsesto, 1:1, Santiago, 2004. 
Varas, Augusto "De la violencia aguda al registro electoral: estrategia y política de alianzas del PC, 1980-1987”, Documentos de Trabajo, FLACSO, 362, Santiago, 1987.

Varas, Pedro, Chile: objetivo del terrorismo, Santiago, Instituto Geográfico Militar, 1988.

Venegas, Hernán, "Trayectoria del Partido Comunista de Chile. De la crisis de la Unidad Popular a la Política de Rebelión Popular de Masas, Revista Universum, 24:2, Talca, 2009.

Vidal, Hernán, Frente Patriótico Manuel Rodríguez. El tabú del conflicto armado en Chile, Santiago, Mosquito Editores, 1996.

\title{
Publicaciones periódicas
}

\author{
Análisis \\ APSI \\ Araucaria de Chile \\ Barricada \\ Basta \\ Boletín del Exterior \\ Boletín de Prensa El Siglo \\ El Mercurio \\ El Rodriguista \\ El Siglo \\ Informe Mensual \\ Revista Principios
}

\section{Documentos y textos del PCCh y FPMR}

La crisis y las condiciones objetivas. Documento editado por el Equipo de la Dirección Interior", Partido Comunista de Chile, Rebelión popular, camino de la victoria, Editado Clandestinamente, Santiago, 1982.

Fundamentos del plan de la SN, sin fecha (1985?)

"Informe al Pleno del Comité Central del Partido Comunista de Chile, 1985. Para voltear a Pinochet el único camino es el enfrentamiento continuo y ascendente", Hacia el congreso nacional, s/e, s/a.

Frente Patriótico Manuel Rodríguez, "A fortalecer la base y los principios rodriguistas construyendo el instrumento patriótico para la revolución", Archivo Histórico Centro de Estudios Miguel Enríquez, CEME, Santiago, 2000.

\section{Entrevistas}

"Carlos"

"Marcelo"

Ramón Vargas 